\title{
BONE MARROW ASPIRATION AND ANEMIA; DIAGNOSTIC IMPORTANCE OF BONE MARROW ASPIRATION AND BIOPSY IN EVALUATING PATIENTS PRESENTING WITH ANEMIA OF UNKNOWN ETIOLOGY.
}

1. MBBS, M.Phil (Hematology) Assistant Professor Pathology Khyber Medical College, Peshawar.

2. MBBS, M.Phil (Hematology) Assistant Professor Pathology Khyber Medical College, Peshawar.

3. $4^{\text {th }}$ year MBBS Student

Federal Medical and Dental College, Islamabad

Correspondence Address: Dr. Muhammad Ihtesham Khan House no. 502, Street 5, Sector F8, Phase-VI, Hayatabad, Peshawar. Ihteshamkhan9@yahoo.com

Article received on: 07/05/2018

Accepted for publication:

$15 / 09 / 2019$

\begin{abstract}
Muhammad Ihtesham Khan ${ }^{1}$, Asif Hussain Munir², Syeda Hina Fatima ${ }^{3}$
\end{abstract}
ABSTRACT... Objectives: To determine the diagnostic importance of bone marrow aspiration and biopsy in work up of cases presenting with anemias of unknown etiology. Study Design: Cross sectional descriptive study. Setting: Pathology Department, Khyber Teaching Hospital, Peshawar. Period: July 2015 to July 2017 (two year). Material \& Methods: All patients presenting with anemia (Hemoglobin less than $12 \mathrm{gm} / \mathrm{dL}$ for females and $13 \mathrm{gm} / \mathrm{d} \mathrm{L}$ for males), whose cause cannot be established on clinical history, examination and blood counts, and were thus referred for bone marrow examination for further workup were included in the study. Patients having malignancies, chemotherapy or radiotherapy associated marrow suppression, and those with diluted marrow unfit for comments were excluded from the study. Bone marrow aspiration and biopsy was done, slides were examined, and diagnoses was made and recorded. The results were drawn accordingly. Results: A total of 199 patients were referred for bone marrow aspiration, presenting with unexplained anemia, during the study period. About 12 patients had blast cells on peripheral blood film, giving diagnosis of leukemia. So they were excluded from the study. Remaining 187 cases were included in the study. The age of the study sample ranged 3 years to 63 years (mean age 42 years $\pm 8.1 \mathrm{SD}$ ). There were $96(51 \%)$ males and 91 (49\%) females. Male to female ratio was 1.05:1. Out of 187 cases presenting with unexplained anemias, about $44(23.5 \%)$ cases were of iron deficiency anemia, 39(20.7\%) cases were of anemia of chronic disorder, $16(8.7 \%)$ cases as hemolytic anemia, about 19 (10.3\%) cases as aplastic anemia, and $52(27.8 \%)$ cases of megaloblastic anemia on bone marrow examination. Conclusion: Bone marrow aspiration and biopsy successfully gives the final diagnosis in cases of anemia where cause cannot be found by routine lab investigations. It helps physician decide further management plan of the patients. So, it should be done in all cases with unexplained anemia.

Key words: Anemia, Aplastic Anemia, Bone Marrow Aspiration, Hemolytic Anemia, Megaloblastic Anemia, Myelodysplasia.

Article Citation: Khan MI, Munir AH, Fatima SH. Bone marrow aspiration and anemia; Diagnostic importance of bone marrow aspiration and biopsy in evaluating patients presenting with anemia of unknown etiology. Professional Med J 2020; 27(2):419-423. DOI: 10.29309/TPMJ/2020.27.2.4476

\section{INTRODUCTION}

Bone marrow aspiration biopsy is an important investigation which helps in the diagnoses of a number of haematological disorders. ${ }^{1,2}$ Usually, the history and examination of the patient make it possible to reach to the probable diagnosis in most of the cases. ${ }^{3}$ But sometimes, history, examination and basic laboratory tests do not help the physician to reach the final diagnosis. In these cases, bone marrow examination is advised to reach the final diagnosis. ${ }^{1}$

Anemia is a hematological disorder that is quite common in the general population, especially in the older population. ${ }^{4,5}$ The prevalence of anemia is $17 \%$ worldwide. ${ }^{1}$ The prevalence is increasing gradually all over the world as the age of the population is increasing. ${ }^{6,7,8}$ World Health Organization defines anemia as a hemoglobin level of less than $13 \mathrm{~g} / \mathrm{dl}$ in males and $12 \mathrm{~g} / \mathrm{dl}$ in females. ${ }^{1}$ It is important to know the specific etiology for anemia, because many causes of anemia are treatable. ${ }^{4}$ Thus it becomes possible to prevent the adverse outcomes on patients if the cause is corrected ${ }^{4}$ Anemia often remains unexplained despite clinical history, 
physical examination, and preliminary laboratory tests. ${ }^{4,9,10,11}$ In such cases, the underlying cause of anemia cannot be established by routine laboratory tests. ${ }^{1}$ Unexplained anemias are usually referred to bone marrow aspiration and biopsy for further workup. ${ }^{9}$

Evaluation for anemia of unknown etiology is a common problems seen in clinical practice. ${ }^{9,11}$ It is becoming a problem for the clinicians all over the world as it poses a diagnostic challenge. ${ }^{1}$ The prevalence of unexplained anemias is quite high.,12 In about $10-24 \%$ cases of anemias, the cause cannot be established on history and examination..$^{1,12}$ Usually, the evaluation of anemia is easy and cause can be found in patients with a single cause of anemia. ${ }^{9,11}$ But in many cases , the cause is not apparent and multiple conditions may be contributing to causing anemia.9,11

The present study was done to highlight the diagnostic importance of bone marrow aspirate and biopsy in establishing the cause of unexplained anemia with unknown etiology.

\section{OBJECTIVE}

This study was done to determine the diagnostic importance of bone marrow aspiration and biopsy in work up of cases presenting with anemias of unknown etiology.

\section{Setting}

The study was done in Pathology department, Khyber Teaching Hospital, Peshawar

\section{Study Period}

The study was done from July 2015 to July 2017 ( 2 years study duration)

\section{Sampling Technique}

Sampling was done by non-probability purposive sampling.

\section{Inclusion Criteria}

All patients presenting with anemia (Hemoglobin less than $12 \mathrm{gm} / \mathrm{dL}$ for females and $13 \mathrm{gm} / \mathrm{dL}$ for males) ${ }^{9}$, whose cause cannot be established on clinical examination and blood counts, and were thus referred for bone marrow examination for further workup were included in the study.

\section{Exclusion Criteria}

Patients having suspicion of leukemia, lymphoma, and those on chemotherapy or radiotherapy associated marrow suppression were excluded from the study.

\section{Study Design}

It was a Cross sectional descriptive study.

\section{Procedure}

Bone marrow aspiration and biopsy was done in a single sitting using local anesthesia from posterior superior iliac spine. The sample obtained was spread on slides. Slides were prepared and stained with wright stain. Iron stain was done using Prussian blue stain. Slides were examined and diagnoses was made and recorded. The results were drawn accordingly.

\section{RESULTS}

A total of 199 patients were referred to pathology department for bone marrow aspiration during the study period. About 12 patients had blast cells on peripheral blood film, giving diagnosis of leukemias. So those cases were excluded from the study. Remaining 187 cases were included in the study. The age range of study sample was 3-63 years, with a mean of 42 years. There were 96(51\%) males and 91 (49\%) females. Male to female ratio was 1.05:1.

The following table shows different diagnoses for unexplained anemia in 187 cases as diagnosed through bone marrow aspiration and biopsy.

\begin{tabular}{|l|c|}
\hline \multicolumn{1}{|c|}{ Final Diagnosis } & n (\%) \\
\hline Iron Deficiency Anemia & $44(23.5 \%)$ \\
Anemia of chronic disorder & $39(20.7 \%)$ \\
Hemolytic anemia & $16(8.7 \%)$ \\
Aplastic anemia & $19(10.3 \%)$ \\
Mixed deficiency Anemia & $17(9 \%)$ \\
Megaloblastic anemia & $52(27.8 \%)$ \\
\multicolumn{2}{|c|}{ Table-I. Bone marrow diagnoses of anemia of } \\
\multicolumn{2}{|c|}{ unknown etiology in 187 cases. }
\end{tabular}

\section{DISCUSSION}

Evaluation for anemia of unknown etiology is a 
common problem in clinical practice..$^{9,11}$ There are many causes of anemia. ${ }^{4}$ In most of the cases, the cause or final diagnosis of anemia can be made from clinical history, physical examination and studying basic hematological parameters. ${ }^{2,4}$ But in some cases, the cause cannot be found, and clinicians have to refer patients for bone marrow for further workup. ${ }^{4,9}$ If anemia of unknown etiology is left undiagnosed, it results in increased morbidity and mortality.,13 Therefore, it is important to find its etiology through further workup. ${ }^{4,9}$

Anemia is a major health problem all over the world. $^{1,2}$ It greatly impairs quality of life of the patients, especially those with the older age. ${ }^{14}$ It causes heart diseases in elders, lack of sleep and changes in the mood. ${ }^{15}$ Literature has even declared it as a marker of death. ${ }^{1,16}$ It is proposed that there is a significant association between anemia and death. ${ }^{17}$ This becomes more alarming in elderly individuals, where anemia leads to poor outcome. ${ }^{1,18}$ Unexplained anemia is always indicating towards a hidden disease. ${ }^{1}$ It is important to do proper workup of such cases to reach to the final causes of anemia. ${ }^{1}$

The present study included those anemic patients in whom the underlying cause could not be determined despite proper clinical history, physical examination and basic hematological parameters. The clinicians referred these cases for bone marrow aspiration and biopsy to help establishing cause of anemia, or to get guidance regarding further investigations.

In our study, the Iron deficiency anemia was seen in $44(23.5 \%)$ cases. Iron deficiency anemia is the commonest anemia all over the world. ${ }^{1}$ Common cause of iron deficiency is inadequate intake of iron in diet. ${ }^{1}$ Other causes of iron deficiency are malabsorption from intestines and intake of certain drugs that impair iron absorption. ${ }^{19}$ In older patients with iron deficiency anemia, it is mandatory to rule out malignancy of the stomach. ${ }^{1}$ History of intake of aspirin should always be taken to rule out bleeding gastric ulcers. ${ }^{1}$ The improvement of dietary habits and intake of iron in diet alone is sufficient to prevent development of the iron deficiency anemia. ${ }^{20}$ In such cases, we suggested to perform serum ferritin levels, hemoglobin electrophoresis and iron levels. Thus, after bone marrow aspiration biopsy gave the final diagnosis, further management plan was made for these patients.

Anemia of chronic disorder was seen in 39 (20.7\%) cases in the present study. Haemoglobin in these patients was low, but bone marrow iron stores were increased. In chronic inflammation, there is upregulation of hepcidin. ${ }^{1}$ Hepcidin decreases iron absorption from the duodenum and release of iron from macrophages. ${ }^{1}$ Also, there is inhibition of release of erythropoietin from the kidney due to cytokines. ${ }^{1,21}$ This also decreases the erythropoiesis. Recent studies suggest that in inflammatory states, there is phagocytosis of the erythroid cells which further decrease the red cell count. ${ }^{1,22}$ The hepcidin is also elevated in cancers and chronic kidney diseases. ${ }^{23,24}$ Clinicians were informed that that anemia in these patients is due to some underlying chronic inflammatory process. In anemia of chronic disorder, iron is available but it cannot be incorporated in globin chain of hemoglobin molecule. ${ }^{1}$

Hemolytic anemia was seen in 16 (8.7\%) cases in the present study. Hemolytic anemias may be common in autoimmune disorders. ${ }^{1,2}$ So, we advised such patients to do Coombs test and autoimmune profile. Other tests suggested in such cases include G6PD level and osmotic fragility test.

Aplastic anemia was seen in 19 (10.3\%) cases in the present study. Such patients present with pallor, fever and bruises all over the body. ${ }^{2}$ Aplastic anemia may be congenital or acquired. ${ }^{2}$ Commonly, aplasia in bone marrow occurs due to any viral infection or using any offending drugs. ${ }^{1,2}$ So, we advised the patients to stop any offending drug which may be causing bone marrow aplasia. It is now proposed that an immune defect causes the $\mathrm{T}$ - lymphocytes to cause damage to the marrow hematopoietic cells. ${ }^{2}$ This causes a fall in peripheral blood counts. The congenital bone marrow failure syndromes also lead to aplastic anemia. ${ }^{2}$ These are common in children. ${ }^{2}$ 
Megaloblastic anemia was seen in 52 (27.8\%) cases in our study .Common causes of vitamin B-12 deficiency include poor dietary meat intake, gastrointestinal disorders and malabsorption syndromes ${ }^{1}$.Other causes are anticonvulusant drugs and methotrexate. ${ }^{1}$ It is important to consider the possibility of pernicious anemia in cases where there is a history of chronic gastritis ${ }^{1}$.The cases where the marrow showed megaloblastic changes were advised to perform serum B 12 and folate level. Further, it was advised to the clinicians to find out the cause of B12 deficiency in such cases. They were also advised a trial of vitamin B12 injections. The injections of vitamin B12 can reverse the sign symptoms of megalobastic anemia and also the neurological features. ${ }^{1}$ Thus, it can be seen how bone marrow aspiration examination helped in further workup of patients presenting with anemia.

Thus, it was found that if clinical history, physical examination and routine blood tests could not give final cause of anemia, bone marrow aspiration and biopsy can prove very helpful in giving the definitive diagnosis of anemia. It helps the clinician decide further coarse of management in such cases. Thus bone marrow aspiration and biopsy hold diagnostic significance in work up of unexplained anemia's.

\section{CONCLUSION}

Morphological study of bone marrow aspiration and biopsy made it possible to give such a wide spectrum of diagnoses for patients presenting with single feature of unexplained anemia. It helps physician decide further management plan of the patients, so bone marrow aspiration plays a significant role and should be considered as an important investigation tool to work up unexplained anemia.

\section{Copyright@ 15 Sep, 2019.}

\section{REFERENCES}

1. Stauder R, Valent P, Theurl I. Anemia at older age: Etiologies, clinical implications, and management. Blood. 2018; 131(5):505-14.

2. Alli N, Vaughan J, Patel M. Anaemia: Approach to diagnosis. S Afr Med J 2017; 107(1):23-7.
3. Kuriakose P. Anemia: An approach to evaluation. CHRISMED J Health Res 2015; 2:95-9.

4. Steensma DP. New challenges in evaluating anemia in older persons in the era of molecular testing. Hematology Am Soc Hematol Educ Program. 2016(1):67-73.

5. Vanasse GJ, Berliner N. Anemia in elderly patients: An emerging problem for the 21st century. Hematology Am Soc Hematol Educ Program. 2010: 271-5. doi: 10.1182/asheducation-2010.1.271.

6. Merchant AA, Roy CN. Not so benign haematology: Anaemia of the elderly. $\mathrm{Br} J$ Haematol. 2012; 156(2):173-185.

7. Bach V, Schruckmayer G, Sam I, Kemmler G, Stauder $R$. Prevalence and possible causes of anemia in the elderly: a cross-sectional analysis of a large European university hospital cohort. Clin Interv Aging. 2014; 9:1187-96.

8. Tettamanti M, Lucca U, Gandini F. Prevalence, incidence and types of mild anemia in the elderly: The "Health and Anemia" population-based study. Haematologica. 2010; 95(11):1849-56.

9. Artz AS, Thirman MJ. Unexplained anemia predominates despite an intensive evaluation in a racially diverse cohort of older adults from a referral anemia clinic. J Gerontol A Biol Sci Med Sci. 2011; 66(8):925-32. doi: 10.1093/gerona/glr090.

10. Maerevoet M, Sattar L, Bron D, Gulbis B, Pepersack T. Anemia in the elderly. Rev Med Brux. 2014; 35(4):3617.

11. Andrès E, Serraj K, Federici L, Vogel T, Kaltenbach G. Anemia in elderly patients: New insight into an old disorder. Geriatr Gerontol Int. 2013; 13(3):519-27. doi: 10.1111/ggi.12017.

12. Stauder R, Thein SL. Anemia in the elderly: Clinical implications and new therapeutic concepts. Haematologica. 2014; 99(7):1127-30.

13. Berliner N. Anemia in the elderly. Trans Am Clin Climatol Assoc. 2013; 124:230-7.

14. Balducci L. Anemia, fatigue and aging. Transfus Clin Biol. 2010; 17(5-6):375-81.

15. Hong $\mathrm{CH}$, Falvey $\mathrm{C}$, Harris TB. Anemia and risk of dementia in older adults: Findings from the Health ABC study. Neurology. 2013; 81(6):528-33. 
16. Patel KV, Longo DL, Ershler WBI. Haemoglobin concentration and the risk of death in older adults: Differences by race/ethnicity in the NHANES III follow-up. Br J Haematol. 2009; 145(4):514-23.

17. Zakai NA, French B, Arnold AM. Hemoglobin decline, function, and mortality in the elderly: The Cardiovascular Health Study. Am J Hematol. 2013; 88(1):5-9.

18. Michalak SS, Matysek JR, Hus I, Gil L. Unexplained anemia in the elderly - a real life analysis of 981 patients. Arch Med Sci.2018.82723 DOI:https://doi. org/10.5114/aoms.2019.82723.

19. Ahmed T, Haboubi N. Assessment and management of nutrition in older people and its importance to health. Clin Interv Aging. 2010; 5:207-16.

20. Ullah A, Sohaib M, Saeed F, lqbal S. Prevalence of anemia and associated risk factors among pregnant women in Lahore, Pakistan. Women Health. 2019; 59(6):660-71.
21. Wang $C Q$, Udupa KB, Lipschitz DA. Interferon-gamma exerts its negative regulatory effect primarily on the earliest stages of murine erythroid progenitor cell development. J Cell Physiol. 1995; 162(1):134-8.

22. Theurl I, Aigner E, Theurl M. Regulation of iron homeostasis in anemia of chronic disease and iron deficiency anemia: diagnostic and therapeutic implications. Blood. 2009; 113(21):5277-86.

23. Nemeth E, Ganz T. Anemia of inflammation. Hematol Oncol Clin North Am. 2014; 28(4):671-81.

24. Elzen WP, Craen AJ, Wiegerinck ET,Westendorp RG, Swinkels DW, Gussekloo J et al. Plasma hepcidin levels and anemia in old age. The Leiden 85-Plus Study. Haematologica. 2013; 98(3):448-54.

\begin{tabular}{|c|l|l|l|}
\hline \multicolumn{3}{|c|}{ AUTHORSHIP AND CONTRIBUTION DECLARATION } \\
\hline Sr. \# & \multicolumn{1}{|c|}{ Author(s) Full Name } & Contribution to the paper & Author(s) Signature \\
\hline 1 & Muhammad Ihtesham Khan & Principal Author. \\
\hline 2 & Asif Hussain Munir & Discussion, Proof reading. \\
\hline 3 & Syeda Hina Fatima & Discussion, Proof reading. \\
\hline
\end{tabular}

